Research article

Open Access

\title{
QSAR Study on 6-Substituted Benzimidazoles: An Insight into the Structural Requirement for the Angiotensin II AT1 Receptor Antagonist
}

\author{
Anurekha JAIN ${ }^{*}{ }^{1}$, Subhash C. Chaturvedi ${ }^{2}$
}

${ }^{1}$ B. R. Nahata College of Pharmacy, Rajiv Gandhi Technical University, Mhow-Neemuch Road 458001 Mandasur (M.P.), India.

${ }^{2}$ School of Pharmacy, Devi Ahilya VishawaVidalaya, Takshashila Parser Khandawa Road, 452003 Indore (M.P.), India.

* Corresponding author. E-mail: anurekha_jain@yahoo.com (A. Jain)

Sci Pharm. 2009; 77: 555-565

doi:10.3797/scipharm.0901-30

Published: $\quad$ June $6^{\text {th }} 2009$

Accepted: June $5^{\text {th }} 2009$

Received: January $30^{\text {th }} 2009$

This article is available from: http://dx.doi.org/10.3797/scipharm.0901-30

(C) Jain and Chaturvedi; licensee Österreichische Apotheker-Verlagsgesellschaft m. b. H., Vienna, Austria.

This is an Open Access article distributed under the terms of the Creative Commons Attribution License (http://creativecommons.org/licenses/by/3.0/), which permits unrestricted use, distribution, and reproduction in any medium, provided the original work is properly cited.

\begin{abstract}
With an aim to identify the structural requirements for selective AT1 angiotensin antagonistic activity, a quantitative structure activity relationship (QSAR) analysis was carried out on a series of 6-substituted benzimidazole derivatives. The QSAR expressions were generated using 28 compounds and the predictive ability of the resulting model was evaluated against a test set of 12 compounds. The internal (cross validated squared correlation coefficient) and external consistency (predictive correlation coefficient) of the QSAR model was 0.78 and 0.40 respectively. In the present work QSAR analysis reveals that geometrical, structural, and shape descriptors govern the angiotensin II AT1 antagonistic activity.
\end{abstract}

\section{Keywords}

Nonpeptide Angiotensin II Antagonist • AT1 receptor • QSAR • Hypertension • RAS

\section{Introduction}

The rennin-angiotensin system (RAS) plays a major role in the regulation of blood pressure and electrolyte homeostasis [1]. RAS is a cascade of proteolytic enzymes (renin and angiotensin converting enzyme (ACE)) that result in the production of the systemic hormone angiotensin II (AII). The blockade of RAS with inhibitors of ACE has demonstrated the effectiveness of the reduction of levels of All on cardiovascular and kidney 
heamodynamics, aldosterone production and release, and the absorption of sodium. Antagonists of All constitute an alternative method blocking the RAS. Several peptidic and nonpeptidic All receptor antagonists are known. The therapeutic availability is less for the peptidic All antagonist due to their poor bioavailability; short plasma half-life and partial agonist activity but the nonpeptidic All receptors antagonist lack the defect of peptidic antagonist [2].The therapeutic profile of All receptor antagonist is thought to be similar to that of angiotensin converting enzyme (ACE) inhibitors such as captopril, enalapril, and lisinopril. In addition, since All receptor antagonist does not affect the metabolism of bradykinin so they may not have the side effect of ACE inhibitors, such as dry cough and angiodema. Recently, the QSAR analysis is a highly interested area for designing the compound before synthesis [3-5].

To gain insight into the structural and molecular requirement influencing the A II antagonistic activity, herein we depict QSAR analysis of some 6-substituted benzimidazoles derivative for All antagonistic activity. The relevance of the model used for the design of novel derivatives should be assessed not only in terms of predictivity, either internal or external, but also in terms of their ability to provide a chemical and structural explanation of their binding interaction. These results should provide guidelines for design of more potent and selective All antagonist.

\section{Experimental}

The All receptor antagonistic activity data of 6-substituted benzimidazole derivatives were taken from the reported work of Uwe Ries et al. [6] (Table 1). The biological activity data $\left(\mathrm{IC}_{50}\right.$ in $\left.10^{-7} \mathrm{M}\right)$ was converted to negative logarithmic mole dose $\left(\mathrm{plC} \mathrm{C}_{50}\right)$ for quantitative structure activity relationship (QSAR) analysis. The molecular modeling study was performed using CS ChemOffice [7] version 10 and DRAGON [8] program while the regression analysis was carried out with VALSTAT [9].

The compound Series was divided into training set of 28 compounds and test set of 12 compounds on the basis of structural diversity and with the aim that it should cover the complete range of variation in antagonist activity. The molecular structures of compounds were sketched by using Chem Draw [7] and then ChemUltra [7] used to convert them into 3D structures. The energy minimization of the molecule was done using molecular mechanics (MM2) until the RMS gradient value became smaller than $0.1 \mathrm{kcal} / \mathrm{mol} \AA$. The energy minimized molecules were subjected to the re-optimization via Austin model-1 (AM1) Hamiltonian method until the RMS gradient attained a value smaller than 0.0001 $\mathrm{kcal} / \mathrm{mol} \AA$ using MOPAC. The molecule was saved as MOL file format. Pursuly, the MOL file was used for the calculation of various Descriptors using DRAGON program. The data was used in order to establish a correlation between physicochemical parameters as independent variables and $\mathrm{plC}_{50}$ as dependent variable employing sequential multiple linear regression analysis method by statistical program VALSTAT. In this regression analysis, the program searches all the permutations and combinations sequentially for the data set. The \pm data within the parentheses are the standard deviation, associated with coefficient of descriptors in regression equations. The best model was selected from the various statistically significant equations on the basis of observed squared correlation coefficient $\left(r^{2}\right)$, standard error of estimate (SEE), sequential Fischer test ( $F$ ), bootstrapping squared correlation coefficient $\left(r^{2}\right.$ bs), bootstrapping standard deviation $\left(S_{b s}\right)$, cross validated squared correlation coefficient using leave one out procedure $\left(Q^{2}\right)$, chance 
Tab. 1. Structure, activities and Descriptors of 6-substituted Benzimidazoles used in training and test set<smiles>[R]c1ccccc1-c1ccc(Cn2c(CCC)nc3cc[14c]([R])cc32)cc1</smiles>

\begin{tabular}{|c|c|c|c|c|c|c|c|}
\hline $\begin{array}{l}\text { S. } \\
\text { No. }\end{array}$ & $\mathbf{R}^{1}$ & $\mathbf{R}^{2}$ & $I C_{50}{ }^{a}$ & $\mathrm{plC}_{50}$ & Mor21 $\mathrm{u}^{\mathrm{c}}$ & Mor31uMor14n & $M R^{d}$ \\
\hline 1 & $\mathrm{H}$ & $\mathrm{COOH}$ & 400 & 6.39 & -1.713 & $0.494-0.54$ & 114.416 \\
\hline 2 & $4-\mathrm{CH}_{3}$ & $\mathrm{COOH}$ & 1200 & 5.92 & -1.887 & $0.827-0.543$ & 119.457 \\
\hline 3 & $5-\mathrm{CH}_{3}$ & $\mathrm{COOH}$ & 1200 & 5.92 & -2.076 & $0.572-0.487$ & 119.457 \\
\hline 4 & $6-\mathrm{CH}_{3}$ & $\mathrm{COOH}$ & 850 & 6.07 & -2.076 & $0.572-0.487$ & 119.457 \\
\hline 5 & $7-\mathrm{CH}_{3}$ & $\mathrm{COOH}$ & 480 & 6.31 & -2.099 & $0.865-0.562$ & 119.457 \\
\hline 6 & $4-\mathrm{NH}_{2}$ & $\mathrm{COOH}$ & 1700 & 5.76 & -1.763 & $0.374-0.766$ & 119.116 \\
\hline 7 & $5-\mathrm{NH}_{2}$ & $\mathrm{COOH}$ & 820 & 6.08 & -1.426 & $0.473-0.800$ & 119.116 \\
\hline 8 & $6-\mathrm{NH}_{2}$ & $\mathrm{COOH}$ & 540 & 6.26 & -1.537 & $0.439-0.866$ & 119.116 \\
\hline 9 & $7-\mathrm{NH}_{2}$ & $\mathrm{COOH}$ & 1060 & 5.97 & -1.575 & $0.339-0.367$ & 119.116 \\
\hline 10 & 4-(acetylamino) & $\mathrm{COOH}$ & 5700 & 5.24 & -2.292 & $0.456-0.551$ & 127.498 \\
\hline 11 & 5-(acetylamino) & $\mathrm{COOH}$ & 460 & 6.33 & -1.682 & $0.506-0.916$ & 127.498 \\
\hline 12 & 6-(acetylamino) & $\mathrm{COOH}$ & 180 & 6.74 & -1.662 & $0.654-0.882$ & 127.498 \\
\hline 13 & 7-(acetylamino) & $\mathrm{COOH}$ & 1800 & 5.74 & -2.074 & $0.360-0.699$ & 127.498 \\
\hline 14 & $4-\mathrm{NHCONHC}{ }_{6} \mathrm{H}_{11}$ & $\mathrm{COOH}$ & 29300 & 4.53 & -2.425 & $0.204-1.306$ & 150.849 \\
\hline 15 & 5-NHCONHC ${ }_{6} \mathrm{H}_{11}$ & $\mathrm{COOH}$ & 800 & 6.09 & -2.072 & $0.152-1.362$ & 150.849 \\
\hline 16 & $6-\mathrm{NHCONHC}_{6} \mathrm{H}_{11}$ & $\mathrm{COOH}$ & 26 & 7.58 & -2.253 & $0.178-1.162$ & 150.849 \\
\hline 17 & 7-NHCONHC ${ }_{6} \mathrm{H}_{11}$ & $\mathrm{COOH}$ & 160 & 6.79 & -1.976 & $0.436-1.250$ & 150.849 \\
\hline 18 & $6-\mathrm{CH}_{3}\left(\mathrm{CH}_{2}\right)_{4} \mathrm{NH}$ & $\mathrm{COOH}$ & 390 & 6.40 & -2.356 & $0.602-0.453$ & 143.084 \\
\hline 19 & $6-$ (piperidin-1-yl) & $\mathrm{COOH}$ & 160 & 6.79 & -2.496 & $0.556-0.366$ & 136.107 \\
\hline 20 & $6-(n-\mathrm{Bu}-\mathrm{CONH})$ & $\mathrm{COOH}$ & 86 & 7.06 & -2.472 & $0.845-0.832$ & 141.327 \\
\hline 21 & $6-\left(\mathrm{CH}_{3}\right)_{2} \mathrm{NCONH}$ & $\mathrm{COOH}$ & 24 & 7.61 & -2.095 & $0.035-0.925$ & 135.968 \\
\hline 22 & $6-\mathrm{C}_{6} \mathrm{H}_{11} \mathrm{NHCONCH}_{3}$ & $\mathrm{COOH}$ & 26 & 7.58 & -2.381 & $0.552-1.205$ & 150.339 \\
\hline 23 & $\begin{array}{l}\text { 6-[methyl(propyl- } \\
\text { sulfonyl)amino] }\end{array}$ & $\mathrm{COOH}$ & 33 & 7.48 & -2.212 & $0.859-0.757$ & 143.139 \\
\hline 24 & & $\mathrm{COOH}$ & 34 & 7.46 & -2.279 & $0.441-0.632$ & 140.148 \\
\hline 25 & & $\mathrm{COOH}$ & 81 & 7.09 & -2.559 & $0.882-0.701$ & 138.631 \\
\hline 26 & ${ }_{1} \mathrm{NHCONH}$ & Tetrazol-5-yl & 21 & 7.67 & -1.833 & $-0.976 \quad 0.217$ & 161.485 \\
\hline 27 & $6-\mathrm{C}_{6} \mathrm{H}_{11} \mathrm{NHCONCH}_{3}$ & Tetrazol-5-yl & 10 & 8 & -2.764 & $0.703-1.514$ & 166.381 \\
\hline 28 & $6-\left(\mathrm{CH}_{3}\right)_{2} \mathrm{NCONH}$ & Tetrazol-5-yl & 8 & 8.09 & -2.343 & $0.902-0.98$ & 143.246 \\
\hline
\end{tabular}


Tab. 1. (Cont.)

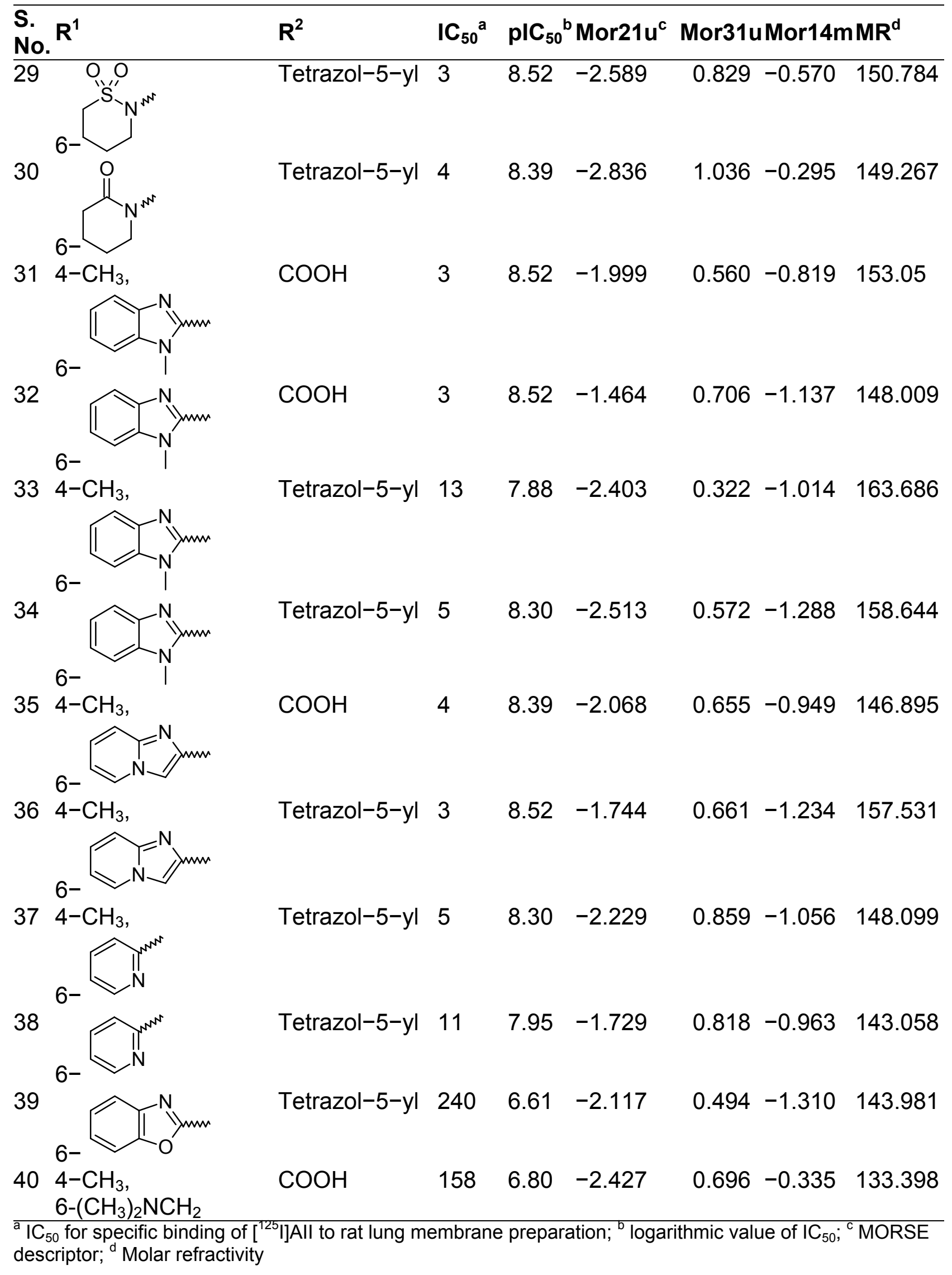


statistics (evaluated as the ratio of the equivalent regression equations to the total number of randomized sets; a chance value of 0.001 corresponds to $0.1 \%$ chance of fortuitous correlation), outliers (on the basis of Z-score value) and predictive squared correlation coefficient of test set $\left(r^{2}\right.$ pred $)$.

\section{Results and Discussion}

In the present study, an attempt has been made to find structural requirement for the antagonistic activity of 6-substituted benzimidazole analogs as All AT1 receptor using the Hansch approach. The multivariant expressions were developed on the basis of adjustable correlation coefficient $\left(r^{2}{ }_{\text {adj }}\right)$. This parameter tells us the statistical significance of incorporated physicochemical descriptor in SEQ-MLR. Adjustable $r^{2}$ takes into account the adjustment of conventional correlation coefficient $\left(r^{2}\right)$. Therefore, if a physicochemical descriptor is added that does not contribute its fair share, the $r^{2}$ adj will actually decline. Adjustable correlation coefficient is a measure of the percentage explained variation in the dependent variable that takes into account the relationship between the number of cases and the number of independent variable in the regression model. Whereas $r^{2}$ will always increase when an independent variable is added, $r^{2}$ adj will decrease if the added variable does reduce the unexplained variation enough to offset the loss of degrees of freedom.

It is necessary that the proposed models should have both the statistical quality as well as good predictive power therefore all the expressions were tested for internal and external validation. Both the validation put forward decision making input for selection of QSAR models. Internal validation was carried out using leave one out (LOO) cross validation method, bootstrapping technique and randomized biological activity test while external validation confirmed with test set data. Tri-variant expressions (Eq. 1 \& 2) which fulfill all the validation criteria up to significant echelon were considered as QSAR model-1 and 2 respectively.

Eq. 1. $\mathrm{plC}_{50}=\operatorname{Mor} 21 \mathrm{u}[1.418( \pm 0.682)]+$ Mor31u $[1.945( \pm 0.635)]+$ Mor14m [1.277 $( \pm 0.618)]+\operatorname{MR}[0.083( \pm 0.0163)]-1.53081( \pm 1.75312)$ $n=28, r=0.919, r^{2}=0.844, S E=0.419, F=31.114$

Eq. 2. $\quad \mathrm{plC}_{50}=\operatorname{Mor} 13 \mathrm{u}[0.854( \pm 0.389)]-\operatorname{Mor} 18 \mathrm{~m}[2.025( \pm 0.702)]-$

Mor28m [3.113 ( \pm 1.658$)]-$ Mor26v $[-2.511( \pm 1.123)]+2.399( \pm 1.122)$ $n=28, r=0.918, r^{2}=0.843, S E=0.421, F=30.834$

Tab. 2. QSAR statistics of significant models

\begin{tabular}{|c|c|c|c|c|c|c|c|c|c|c|c|}
\hline $\begin{array}{l}\text { Model } \\
\text { No. }\end{array}$ & $r^{2 a}$ & $\mathbf{r}^{2}{ }_{a d j}^{b}$ & SEE & $F^{d}$ & $r_{b s}^{2} e^{e}$ & $S_{b s}^{f}$ & Chance & $\mathbf{Q}^{2 \mathrm{~g}}$ & $S_{\text {PRESS }}^{h}$ & $S_{\text {DEP }}{ }^{i} r_{\text {pred }}^{2}$ & Out \\
\hline 1 & 0.84 & 0.82 & 0.41 & $\overline{31.11}$ & 0.85 & 0.058 & 0.001 & 0.78 & 0.40 & 0.400 .40 & Nil \\
\hline 2 & 0.84 & 0.82 & 0.42 & 30.83 & 0.86 & 0.053 & 0.001 & 0.70 & 0.57 & $0.52 \quad 0.15$ & Nil \\
\hline
\end{tabular}

${ }^{\mathrm{a}}$ squared correlation coefficient; ${ }^{\mathrm{b}}$ adjustable correlation coefficient; ${ }^{\mathrm{c}}$ standard error of estimate; ${ }^{\mathrm{d}}$ sequential Fischer test; ${ }^{\mathrm{e}}$ bootstrapping squared correlation coefficient; ${ }^{\mathrm{f}}$ bootstrapping standard deviation; ${ }^{\mathrm{g}}$ cross validated squared correlation coefficient using leave one out procedure; ${ }^{\mathrm{h}}$ squared sum of predicted residual; i standard error of prediction; ${ }^{j}$ predictive squared correlation coefficient of test set. 
Both the models have correlation coefficient more than ( $r=0.900)$, which accounts for more than $84 \%$ of the variance in the activity. The inter-correlation among the parameters used in model no. 1 is less than 0.370 (Table $2 \& 3$ ).

Tab. 3. Inter-correlation matrix of descriptors used in model 1

$\begin{array}{lllll}\text { Descriptors } & \text { Mor21u } & \text { Mor31u } & \text { Mor14m } & \text { MR } \\ \text { Mor21u } & 1.000 & & & \\ \text { Mor31u } & 0.285 & 1.000 & & \\ \text { Mor14m } & 0.157 & 0.294 & 1.000 & \\ \text { MR } & 0.370 & 0.242 & 0.258 & 1.000\end{array}$

The model shows, that in a multi-variant model, a dependent variable can be predicted from a linear combination of the independent variables. The $P$ value is less than 0.01 for each physiochemical parameter involved in model generation. The data showed overall internal statistical significance level better than $99.9 \%$ as it exceeded from the tabulated $F_{(4,25 \alpha 0.001)}=10.8$. Models were further tested for outliers by Z-score method and no compound was found to be an outlier (Table 2) which suggested that the models are able to explain the structurally diverse analogs that is helpful in designing of more potent compounds using physiochemical parameters.

The Z-value for individual compounds within the specific range $(<j 2.5 \mathrm{j})$ indicated absence of outliers.

It is used to label the outliers in the dataset.

$$
z_{i}=\frac{\left(x_{i}-\bar{x}\right)}{s}
$$

where

$$
s=\sqrt{\frac{\sum_{i-1}^{n}\left(x_{i}-\bar{x}\right)^{2}}{n-1}}
$$

Where,

$n=$ Number of datapoints

$x_{i}=$ estimated value of predicted

$\bar{x}=$ Mean of observed values of predicted

Only high correlation coefficient is not enough to select the equation as a model and hence various statistical approaches were used to confirm the robustness and practical applicability of the equations. Model $1 \& 2$ showed that their probability of chance correlation is less than $0.1 \%$ in randomized biological activity test. Bootstrapping technique was employed to confirm the contribution of descriptors to the activity. They were equi-intense or of different rank. The value of bootstrapping squared correlation coefficient and bootstrapping standard deviation implies that the equations are proper representative of the group of analogs (Table 2). 
The internal consistency of the training set was confirmed by using leave one out (LOO) cross validation method to ensure the robustness of the Model. Models showed good internal consistency $\left(Q^{2}=0.70 \& 0.78\right.$ see table 2$)$, which reduces the probability of coincidental correlation of the expression (Table 4, Figure1). Although model showed good internal consistency, they may not be applicable for the analogs which were never used in the generation of the correlation. Therefore, the external extrapolation power of the model was further authenticated by a test set of twelve compounds. Values of predictive squared correlation coefficient $\left(r^{2}\right.$ pred) are 0.40 and 0.15 for model. $1 \& 2$ respectively (see Table 2$)$

Tab. 4. Calculated and Predicted $\mathrm{pIC}_{50}$ (by LOO method) of training set with residual and $Z$-score value using model 1

\begin{tabular}{|c|c|c|c|c|c|}
\hline \multirow{2}{*}{$\begin{array}{l}\text { Comp } \\
\text { No. }\end{array}$} & \multicolumn{5}{|c|}{ Model } \\
\hline & $\begin{array}{l}\text { Calculated } \\
\text { plC }_{50}\end{array}$ & Residual & $\begin{array}{l}\text { Z-valu } \\
\text { e }\end{array}$ & $\begin{array}{l}\text { Predicted } \\
\text { plC }_{50} \text { (loo) }\end{array}$ & $\begin{array}{l}\text { Residual } \\
\text { (loo) }\end{array}$ \\
\hline $\mathrm{T}-1$ & 5.79 & 0.60 & 1.56 & 5.68 & 0.71 \\
\hline $\mathrm{T}-2$ & 6.60 & -0.68 & -1.77 & 6.70 & -0.78 \\
\hline$T-3$ & 5.91 & 0.01 & 0.01 & 5.91 & 0.01 \\
\hline $\mathrm{T}-4$ & 5.91 & 0.16 & 0.40 & 5.89 & 0.18 \\
\hline$T-5$ & 6.35 & -0.04 & -0.09 & 6.36 & -0.05 \\
\hline $\mathrm{T}-6$ & 5.58 & 0.18 & 0.46 & 5.55 & 0.21 \\
\hline $\mathrm{T}-7$ & 6.21 & -0.13 & -0.33 & 6.24 & -0.16 \\
\hline $\mathrm{T}-8$ & 5.90 & 0.36 & 0.92 & 5.84 & 0.42 \\
\hline $\mathrm{T}-10$ & 5.96 & -0.72 & -1.87 & 6.07 & -0.83 \\
\hline $\mathrm{T}-11$ & 6.46 & -0.13 & 0.32 & 6.47 & -0.14 \\
\hline $\mathrm{T}-15$ & 6.58 & -0.49 & -1.26 & 6.79 & -0.70 \\
\hline $\mathrm{T}-17$ & 7.41 & -0.62 & -1.61 & 7.51 & -0.72 \\
\hline $\mathrm{T}-19$ & 6.82 & -0.03 & -0.06 & 6.82 & -0.03 \\
\hline $\mathrm{T}-20$ & 7.25 & -0.19 & 0.49 & 7.27 & -0.21 \\
\hline $\mathrm{T}-22$ & 7.08 & 0.50 & 1.29 & 6.98 & 0.60 \\
\hline $\mathrm{T}-23$ & 7.89 & -0.41 & -1.07 & 7.94 & -0.46 \\
\hline $\mathrm{T}-24$ & 6.90 & 0.56 & 1.46 & 6.86 & 0.6 \\
\hline $\mathrm{T}-26$ & 7.63 & 0.04 & 0.12 & 7.20 & 0.47 \\
\hline $\mathrm{T}-28$ & 7.51 & 0.58 & 1.49 & 7.46 & 0.63 \\
\hline $\mathrm{T}-30$ & 8.45 & -0.06 & 0.14 & 6.48 & 1.91 \\
\hline $\mathrm{T}-31$ & 8.36 & 0.16 & 0.41 & 8.33 & 0.19 \\
\hline $\mathrm{T}-32$ & 8.57 & -0.05 & 0.14 & 8.61 & -0.09 \\
\hline $\mathrm{T}-33$ & 7.95 & -0.07 & -0.18 & 7.97 & -0.09 \\
\hline $\mathrm{T}-35$ & 7.77 & 0.62 & 1.61 & 7.72 & 0.67 \\
\hline $\mathrm{T}-37$ & 7.90 & 0.40 & 1.02 & 7.85 & 0.45 \\
\hline $\mathrm{T}-38$ & 8.23 & -0.28 & -0.71 & 8.30 & -0.35 \\
\hline $\mathrm{T}-39$ & 6.68 & -0.07 & 0.17 & 6.70 & -0.09 \\
\hline $\mathrm{T}-40$ & 7.00 & -0.20 & -0.53 & 7.03 & -0.23 \\
\hline
\end{tabular}




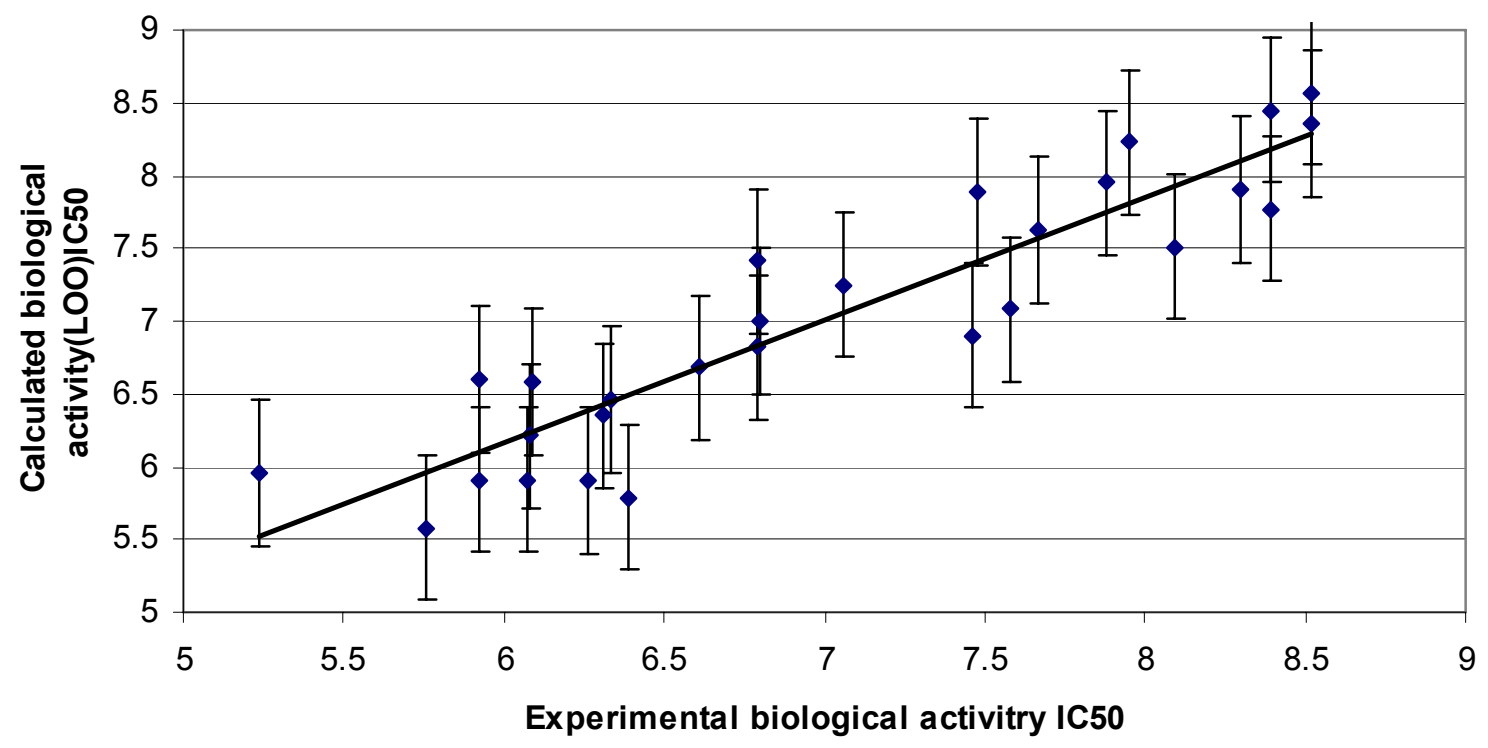

Fig. 1. A plot between observed $\mathrm{plC}_{50}$ and calculated (LOO) $\mathrm{plC}_{50}$ with residual using model 1

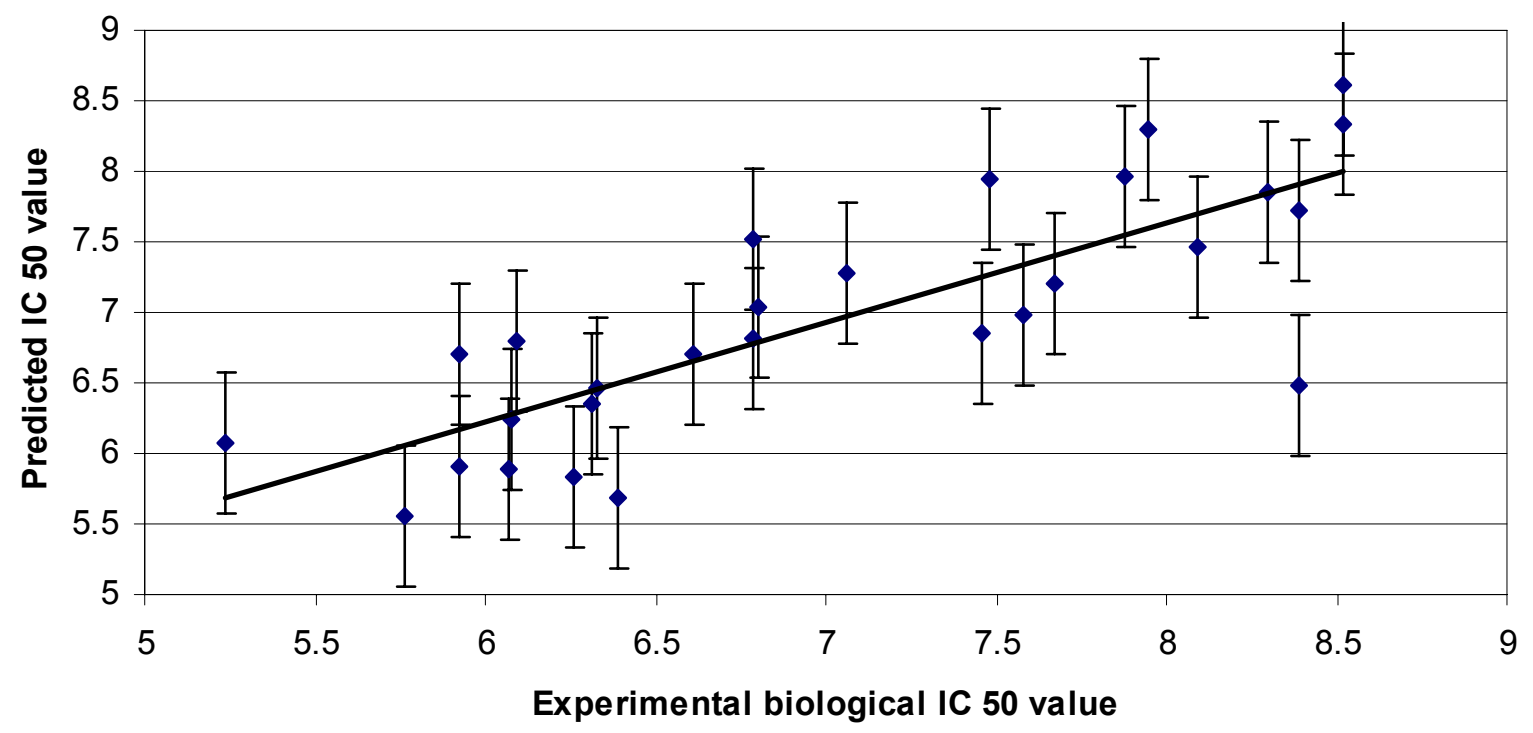

Fig. 2. A plot between observed $\mathrm{plC}_{50}$ and predicted ( $\mathrm{LOO}$ ) $\mathrm{plC}_{50}$ with residual using model 1

The test set supported significantly the robustness, predictiveness and wide applicability of the model 1 over model 2 (Table 5 \& Figure 2). In general the model fulfills the statistical validation criteria to the significant extent. 
Tab. 5. Observed and Predicted $\mathrm{plC}_{50}$ of test set with residual using model 2

\begin{tabular}{lccc}
\hline S. No. & $\begin{array}{l}\text { Observed } \\
\text { plC }\end{array}$ & $\begin{array}{l}\text { Predicted } \\
\text { plC }_{50}\end{array}$ & Residual \\
\hline Test-9 & 5.97 & 6.29 & -0.32 \\
Test-12 & 6.74 & 6.82 & -0.08 \\
Test-13 & 5.74 & 5.90 & -0.16 \\
Test-14 & 4.53 & 6.25 & -1.72 \\
Test-16 & 7.58 & 6.63 & 0.95 \\
Test-18 & 6.40 & 7.57 & -1.17 \\
Test-21 & 8.52 & 5.65 & 2.87 \\
Test-25 & 7.09 & 7.15 & -0.06 \\
Test-27 & 8.00 & 7.77 & 0.23 \\
Test-29 & 8.52 & 8.17 & 0.35 \\
Test-34 & 8.30 & 7.51 & 0.79 \\
Test-36 & 8.52 & 8.76 & -0.24
\end{tabular}

Mor 21u, Mor31u and Mor14m are 3D molecular representation of structure based on electron diffraction code (MoRSE code) contributing positively to the biological activity. [10-12] was calculated by summing atom weights viewed by a different angular scattering function. The values of these code functions were calculated at 32 evenly distributed values of scattering angle(s) in the range of $0-31 \AA^{-1}$ from the three dimensional atomic co-ordinates of a molecule. The 3D-MoRSE code was calculated using following expression;

$$
I(s)=\sum_{i=2}^{N} \sum_{j=1}^{i-1} A_{i} \cdot A_{j} \cdot \frac{\sin \left(s r_{i j}\right)}{s r_{i j}}
$$

Where,

$s$ is scattering angle

$r_{i j}$ is interatomic distance of $i^{\text {th }}$ and $j^{\text {th }}$ atom

$A_{i}$ and $A_{j}$ are atomic properties of $i^{\text {th }}$ and $j^{\text {th }}$ atom respectively including vander Waals volume, atomic number, atomic mass, partial atomic charges, residual electro-negativities, and atom polarizability.

Model 1 indicates that Molar refractivity [13] is contributing positively to the biological activity showing that the steric interaction play role in receptor binding.

From the discussion it concludes that three dimensional structural properties (MoRSE codes) and molar refractivity of 6-substituted benzimidazole derivative is decisive in AT1 receptor All antagonist activity.

\section{Acknowledgment}

The authors are thankful to the HOD, School of pharmacy, DAVV, Indore for providing facilities to complete this work. 


\section{Authors' Statement}

\section{Competing interest}

The authors declare no conflict of interest.

\section{References}

[1] Gilman G, Goodman SL, Rall TW, Murad F.

In: The Pharmacological Basis of Therapeutics. $7^{\text {th }}$ ed.

New York: Macmillan Publishing Co, 1985: 639-659.

[2] Smith RD, Chiu AT, Wong PC, Herblin WF, Timmermans PBMWM.

Pharmacology of Nonpeptide Angiotensin II Receptor Antagonist.

Ann Rev Pharmacol Toxicol. 1992; 32: 135-165.

doi:10.1146/annurev.pa.32.040192.001031

[3] Pandya T, Pandey SK, Tiwari M, Chaturvedi SC, Saxena AK.

$3 \mathrm{D}-\mathrm{QSAR}$ studies of triazolinone based balanced $\mathrm{AT} \mathrm{T}_{1} / \mathrm{AT}_{2}$ receptor antagonist.

Bioorg Med Chem. 2001; 9: 291-300.

doi:10.1016/S0968-0896(00)00243-1

[4] Pandya T, Chaturvedi SC.

Structure-activity relationship study of some triazolinone based compounds with antagonistic balanced activity on angiotensin II receptor subtypes AT1 and AT2. A three-dimensional quantitative structure-activity relationship investigation.

Arzneimittelforschung. 2005; 55: 265-270.

PMid:15960425

[5] Jain A., Chaturvedi SC.

Rationalization of Physicochemical property of some substituted benzimidazole bearing acidic heterocyclic towards angiotensin II antagonist: a QSAR approach.

Asian J Biochem. 2008; 3: 330-336.

doi:10.3923/ajb.2008.330.336

[6] Uwe JR, Gerhard M, Berthold N, Kain MH, Helmut M, Michael E, Jecobus CA, Vanmeel W, Nobert $\mathrm{HH}$.

6-Substituted benzimidazoles as new nonpeptide angiotensin II receptor antagonists: synthesis, biological activity, and structure-activity relationships.

J Med Chem. 1993; 36: 4040-4051.

doi:10.1021/jm00077a007

[7] CS Chem Office, version 8.0.

Cambridge soft Corporation, software publishers association, $1730 \mathrm{~m}$ Street, suite 700, Washington DC 20036, USA.

[8] Todeschini R, Consonni V.

DRAGON-Software for the calculation of molecular Descriptors.

2001; rel. 1.12 for Windows.

[9] Gupta AK, Arokia BM, Khakhedikar SG.

Valstat: validated program for Quantitative structure activity relation ship studies.

Indian J Pharm Sci. 2004; 66: 396-402.

[10] Gasteiger J, Sadowski J, Schuur J, Selzer P, Steinhauer L, Steinhauer V.

Chemical information in 3D space.

J Chem Inf Comput Sci. 1996; 36: 1030-1037.

doi:10.1021/ci960343+ 
[11] Schuur J, Selzer HP, Gasteiger J.

The coding of the three -dimensional structure of molecules by molecule transform and its application structure-spectra correlation and studies of biological activity.

J Chem Inf Comput Sci. 1996; 36: 334-344.

doi:10.1021/ci950164c

[12] Schuur J, Gasteiger J.

Infrared spectra simulation of substituted benzene derivatives on the basis of a 3D structure representation.

Anal Chem. 1997; 83: 2398-2405.

doi:10.1021/ac9611071

[13] Viswanadhan VN,Ghose AK, Ravankar GR, Robins RK.

Atomic physicochemical parameters for three dimensional structure directed quantitative structure-activity relationships. 4. Additional parameters for hydrophobic and dispersive interactions and their application for an automated superposition of certain naturally occurring nucleoside antibiotics.

J Chem Inf Comput Sci. 1989; 29: 163-172.

doi:10.1021/ci00063a006 